\title{
AS INFLUÊNCIAS DOS ORGANISMOS INTERNACIONAIS NAS POLÍTICAS DESENVOLVIDAS NO SISTEMA EDUCACIONAL BRASILEIRO E NO ESTADO DO PARANÁ*
}

Juliana Fatima Serraglio Pasini

\section{Introdução}

Este capítulo apresenta um recorte da pesquisa realizada para tese de doutorado onde discuto as influências dos organismos internacionais nas políticas desenvolvidas no sistema educacional brasileiro e no estado do Paraná, em específico, o desenvolvimento do sistema de avaliação em larga escala e compreender como as políticas de âmbito federal são incorporadas, adaptadas e aprimoradas em âmbito estadual refletindo na operacionalização do sistema educacional e criação do sistema próprio de avaliação em larga escala. O percurso metodológico da pesquisa foi pesquisa qualitativa, incluiu análise de documentes e pesquisa bibliográfica. Como resultado da pesquisa fica evidente que influencia dos Organizamos Internacionais resultou na implementação de políticas compensatórios, que seguem princípios como gerencialismo, performatividade e produtividade no contexto educacional no Estado do Paraná.

As bases teóricas de sustentação aos conceitos trabalhados na pesquisa ancoram-se em diferentes autores, dada a necessidade de vários olhares que possam conduzir à compreensão acerca da avaliação sob uma perspectiva macroanalítica, a fim de estabelecer análises sobre as estruturas sócio-histórica, política e econômica como condicionantes das relações estabelecidas nas distintas esferas educacionais.

No campo educacional, os organismos internacionais ganham espaço, na busca de conduzir a educação na América Latina ao ideário neoliberal, por meio de financiamentos e orientações para as reformas necessárias à América Latina.

Compreender a institucionalização das políticas de avaliação, vinculada ao contexto econômico e político, leva a compreender como estas passam a ser operacionalizadas no contexto da prática. Essa pesquisa apresenta a influência dos organismos internacionais no desenvolvimento e na implementação das políticas de avaliação no Brasil e o contexto histórico das políticas de avaliação em larga escala, desenvolvidas em âmbito federal e estadual, desde a sua implementação até os seus desdobramentos na política educacional.

${ }^{*}$ DOI - 10.29388/978-65-86678-87-1-0.f.129-147 


\section{A influência dos organismos internacionais nas políticas de avaliação em larga escala no contexto brasileiro}

Neste trabalho, o termo organismos internacionais refere-se, ao sistema das Nações Unidas, sendo a Unesco e a Unicef as agências especializadas em Educação. No entanto, outras organizações internacionais influenciaram fortemente o setor educacional; as principais são Banco Mundial - BIRD e a Organização para o Cooperação e Desenvolvimento Econômico - OCDE.

O Banco Mundial, em virtude da ampla estrutura de agência multilateral, possui cerca de 180 países sócios; como aponta Fonseca (2013), firmou assim sua presença mundial como agente financiador de projetos para os setores público e privado. No caso brasileiro, os créditos oriundos do BIRD constituem pouco mais de $10 \%$ da dívida externa do País. A presença do Banco se faz pela sua atuação para além da chamada assistência econômica, pela qual são realizadas as concessões de créditos não apenas para os projetos educacionais, mas para infraestrutura, energia, transportes, saneamento e urbanização.

No Brasil, a atuação do Banco Mundial, por meio da internacionalização de políticas educativas de organismos internacionais como a UNESCO, bem como da OCDE, iniciou-se na década de 1970, mas se concretizaram efetivamente nos anos de 1990 (FONSECA, 2013).

O crescimento expressivo da participação do Banco Mundial no projeto educacional brasileiro deu-se na década de 1990, por sua atuação na organização da Conferência Mundial de Educação para Todos, realizada na

Tailândia em 1990, sob a coordenação do BIRD, do PNUD, da UNICEF e da UNESCO. A conferência reuniu 155 países e 150 entidades não governamentais.

Como explica Fonseca,

[...] o Banco declarou-se como o principal sponsor da Conferência Mundial de Educação para Todos, além de ser colocado como coordenador da cooperação técnica internacional e educação.

A conferência de Nova Délhi, realizada em 1993, deu continuidade ao debate sobre a proposta internacional iniciada em 1990, desta vez, congregando os nove países mais populosos do mundo: Brasil, México, China, Índica, Paquistão, Bangladesh, Egito, Nigéria, Indonésia (FONSECA, 1998, p. S/N).

Ambas as conferências convergem em proposições para novos modelos de gestão do ensino público, calcados em formas mais flexíveis, participativas e descentralizadas de administração de recursos e das responsabilidades, incluindo a participação da empresa privada na gestão do ensino público. As orientações da Conferência de Nova Délhi foram incorporadas no Plano Decenal Brasileiro para Educação, com o compromisso de "atender as necessidades básicas de aprendizagem de todos os nossos povos tornando universal a educação básica e ampliando oportunidades de aprendizagem para crianças, jovens e adultos" (MEC, 1993-2003, p. 
121). Da mesma forma, a LDB $9394 / 1996$ faz menção à garantia de padrão de qualidade da educação, em seu artigo 3으, parágrafo IX.

Outro evento importante foi 24a Reunião da Comissão Econômica para América Latina e Caribe - CEPAL (Reunião de Economia e Finanças), em 1992, [...] onde a educação foi apresentada por meio do Documento Educação e Conhecimento: Eixo de Transformação Produtiva com Equidade como a única política pública capaz de garantir o desenvolvimento social e econômico de uma nação (GONÇALVES, 2005, p. 40).

Seguindo a lógica da cidadania, equidade e competitividade, os documentos da Comissão Econômica da CEPAL dos anos de 1990 recomendavam que os países da região passassem a investir em reformas do sistema educativo com vistas ao sistema produtivo, por meio do desenvolvimento de competências e habilidades específicas dos alunos, como versatilidade, capacidade de inovação, comunicação e flexibilidade. A CEPAL defendeu amplamente a capacitação e a formação da tecnologia e da ciência, porém, não houve garantia de seus resultados, de acordo com Gonçalves (2005). O que ocorreu foi uma grande inserção da gestão empresarial, com ênfase na garantia dos resultados educacionais, com enfoque no desenvolvimento de um modelo de avaliação com convergência para os resultados.

O evento de análise do Projeto Principal da Educação para América Latina e Caribe - PROMEDLAC $\vee$ foi outro marco importante, por meio de uma reunião de Ministros de Educação convocados pela UNESCO, em 1993, com vistas à melhoria dos níveis de qualidade das aprendizagens.

Já o Programa de Promoção da Reforma Educativa na América Latina (PREAL) propiciou o avanço intenso das políticas de avaliação em larga escala, como norte para o desenvolvimento das políticas educacionais. O PREAL, em 1996, "se tornou a principal voz não governamental a manifestar-se sobre a educação na América Latina e um forte defensor do envolvimento das lideranças da sociedade civil nos esforços pela reforma educacional" (GONÇALVES, 2005, p.42). A principal ação desse evento culminou no debate sobre as possibilidades para melhorar a qualidade e a equidade da educação, inclusive identificar e divulgar as melhores práticas e propostas para monitorar o progresso das iniciativas de melhorias no contexto educacional.

O relatório apresentado por Laurene Wolf, em 4 de dezembro de 1996, desenvolvido pelo Banco Mundial - "Desenvolvendo Sistemas de Avaliação Educacional na América Latina" -, visou a divulgar as práticas e as melhorias da qualidade do ensino a partir da experiência do México, do Chile, da Colômbia e da Costa Rica. A partir desses eventos, estruturou-se um solo fértil para o desenvolvimento do sistema de avaliação atrelado aos resultados, tanto em nível federal, quanto estadual e municipal. No Brasil da década de 1990, a educação passa a seguir a mesma lógica. Passa a defender uma reforma administrativa para criar um "Estado mínimo", afirmando que, se não for dessa forma, o País poderá não fazer parte da "nova ordem mundial".

O projeto educacional do neoliberalismo tem como premissa uma reforma economicista da Educação; propõe que ela se preste ao desempenho individual no mercado e ao crescimento econômico (SOLIGO, 2013). A educação está intrinsecamente ligada ao padrão de qualidade, que está atrelada aos princípios de eficiência e 
eficácia na educação. Nesse contexto, inserem-se as políticas de avaliação em larga escala; é por meio delas que se buscarão formas de garantir a eficiência e a produtividade. Assim, o Estado passa a ser o principal agente regulador no campo educacional.

A orientação do Banco Mundial refere-se à adoção de critérios gerenciais e de eficiência, para que seja alcançada a almejada a "qualidade da educação". O Banco Mundial refere-se ao conceito de qualidade formulado por economistas, que é específico do mundo dos negócios, em sua proposta de reforma educativa. O conceito está expresso no documento intitulado "Prioridades y estratégia para la educación":

A qualidade da educação é difícil de definir e de medir. Em uma definição satisfatória devem inclui os resultados obtidos pelos alunos. Os resultados da educação podem melhorar mediante adoção de quatro importantes medidas: a) o estabelecimento de normas sobre os resultados da educação; b) a prestação de apoio aos insumos que, segundo se sabe, melhoram o rendimento; c) a adoção de estratégias flexíveis para a aquisição e a utilização dos insumos e; d) a vigilância dos resultados (BANCO MUNDIAL, 1996, p. 51).

Nesse contexto, é implementado o Sistema de Avaliação da Educação Básica SAEB, na década de 1990, como uma política pública educacional, cujo principal objetivo se efetiva em contribuir "para melhorias da qualidade da educação brasileira e para a universalização do acesso à escola, oferecendo subsídios concretos para formulação, reformulação e monitoramento das políticas públicas voltadas para a educação básica" (INEP, 2002, p. 9).

Percebe-se, a grande influência dos organismos internacionais, em especial do BIRD no delineamento das políticas educacionais brasileiras, bem como sua influência na criação de programas e projetos que tornem a educação mais eficiente sob as três óticas: do gerencialismo, da performatividade e da regulação.

O gerencialismo, para Ball (2005), representa uma nova forma de administrar os setores públicos por meio de uma cultura empresarial, mercantil e objetiva. 0 autor destaca que o gerencialismo é um mecanismo central da reforma, pois essa tecnologia

[...] desempenha o importante papel de destruir os sistemas éticoprofissionais que prevaleciam nas escolas, provocando sua substituição por sistemas empresariais competitivos. [...]. 0 gerencialismo busca incutir a performatividade na alma do trabalhador (BALL, 2005, p. 544-545).

Ou seja, o gerencialismo cria um ambiente adequado para desenvolver a cultura da performatividade no espaço educativo. As iniciativas de avaliação em larga escala no Brasil iniciaram na década de 1980, no Ministério da Educação, no período de redemocratização política do País. Esse período trouxe para o debate vários aspectos importantes, como o acesso à escola e à qualidade do ensino ofertada à 
população. No entanto, de acordo com Freitas (2007), o interesse pela avaliação sistêmica, na organização do setor educacional, já se manifestava desde a década de 1930, com as avaliações pedagógicas e psicopedagógicas.

Os delineamentos da implementação do sistema de avaliação trouxeram muitas mudanças no contexto organizacional escolar, bem como na cultura escolar, modificando as práticas docentes e as ações desenvolvidas em âmbito da gestão escolar. Freitas (2007) afirma que, na década de 1950, foram realizados levantamentos quantitativos acerca da realidade escolar. Segundo a autora,

[...] mapearam a administração das redes de escolas, informaram sobre a situação e funcionamento das escolas, sobre resultados quantitativos do ensino (índices de aprovação, repetência, matrícula e evasão), sobre as relações entre a escola e a realidade local (FREITAS, 2007, p.14).

Ela ressalta que, na década de 1970 , houve pesquisas e projetos financiados pelo INEP, com a finalidade de elaborar currículos, avaliar cursos e programas. Assim, iniciam os primeiros moldes para implantar o sistema de avaliação que temos atualmente.

Em 1987, foi criado o Sistema de Avaliação do Ensino Público de 1o grau SAEP. Com a Constituição de 1988, ficou consolidado o compromisso de garantir à sociedade atendimento educacional, respeito às peculiaridades regionais, desenvolvimento de estratégias em longo prazo, para que fosse efetivado o processo de democratização da escolarização e o acesso ao ensino de qualidade, necessários à formação do indivíduo.

As pesquisas de Heyneman (2011) revelam que o Brasil juntou-se ao mundo das avaliações trinta anos após os Estados Unidos; porém, o que impressiona é número de avaliações realizadas regularmente. O Brasil participa das avaliações internacionais patrocinadas pelo IEA, OCDE e UNESCO, e dispõe de fontes de dados semelhantes aos dados dos Estados Unidos. Além disso, faz parte do Programa Internacional de Avaliação de Estudantes (PISA), sendo este desenvolvido e coordenado pela OCDE, com a finalidade de comparar ao nível de qualidade do ensino, aplicado a estudantes, na faixa de 15 anos de idade, em que se pressupõe o término da educação básica.

O primeiro programa de educação básica proposto pelo Banco Mundial e pela Organização Internacional do Trabalho foi para o Nordeste Brasileiro -o EDURURAL. No mesmo período, em São Paulo, foi lançado o SARESP, desenvolvido pela Secretaria do Estado e Técnicos da Fundação Carlos Chagas. O EDURURAL e o SARESP foram os programas que embasaram a construção do SAEB na década de 1990. As aferições por meio do SAEB iniciam em 1993, com caráter amostral, e, a partir de 1995, o governo incorporou a Teoria de Resposta ao Item - TRI, abrindo a possibilidade de comparabilidade entre os resultados das avaliações.

O primeiro projeto piloto de avaliação foi aplicado no Paraná e no Rio Grande do Norte, realizado pelo Ministério da Educação e Desporto, em 1988, seguido do 
Ceará, com o SPAECE, desde 1992. No Paraná, o Programa de Avaliação - AVA, inicia em 1995 e perdura até 2002; posteriormente, cria-se o SAEP, que inicia em 2012 e continua em andamento.

Em meados da década de 1990, a adoção de política de avaliação em larga escala torna-se um dos eixos centrais das políticas educacionais. A promulgação da Lei de Diretrizes e Bases para Educação Nacional - LDBEN (Lei no 9394/1996) reflete a adesão do governo ao modelo neoliberal. A referida lei atesta a importância das avaliações sistêmicas, fixando sua obrigatoriedade nos diferentes níveis do sistema educacional e a participação do Brasil em projetos internacionais de avaliação comparada, conforme aponta Bonamino (2002).

A institucionalização do sistema de avaliação ganhou destaque em 1996, quando a LDBEN 9394 atribui à União a responsabilidade de "assegurar o processo nacional de avaliação do rendimento escolar no ensino fundamental, médio e superior em colaboração com os sistemas de ensino". Esse regime de colaboração, com maior participação dos estados e dos municípios, fortaleceu a institucionalização de um sistema de avaliação brasileiro; conforme Bonamino (2002), a década de 1990 se caracterizou como "tempo de avaliação".

No que se refere às orientações dos organismos internacionais quanto à educação, Werle (2008) assegura que os níveis de educação estão interligados ao sucesso econômico, decorrente da "[...] intensa rivalidade da economia global e parece estender-se para uma competição internacional entre as escolas, métodos e sistemas educacionais" (WERLE, 2008, p. 173, grifo da autora). Assim, as propostas para a Educação brasileira, segundo esse viés, mantêm relação estreita entre as políticas educacionais desenvolvidas e as determinações de organismos internacionais, como o Banco Mundial.

A avaliação em larga escala, na metade da década de 1990, é organizada sistematicamente no sistema educacional brasileiro, com a criação do Sistema de Avaliação da Educação Básica - SAEB. Este substituiu o SAEP, com a primeira aplicação de provas e o levantamento de dados em nível nacional. O novo sistema obteve assistência nacional, como aponta a pesquisa de Coelho (2008), com a ajuda do PNUD, um projeto com fundos de empréstimo do Banco Mundial que apoiou a implantação e o desenvolvimento do programa, visando a aprimorar o sistema de informações sobre o sistema educacional. As ações foram realizadas em consonância com o projeto BRA-86-002, elaborado pelo Ministério da Educação, Secretaria de Ensino Básica; as ações do projeto e os objetivos constam no relatório intitulado "Alcance e funcionamento do projeto BRA-86002".

O projeto BRA-86-002 permitiu o acesso a tecnologias de avaliação, utilizadas em outros países, e o treinamento de técnicos da área, no País e no exterior. Possibilitou o desenvolvimento de programas de assessorias e de bolsa de estudos no exterior, visando a formar gestores que pudessem estar aptos a "[...] apoiar permanentemente os sistemas educacionais das Unidades Federadas e dos seus municípios, na utilização de técnicas, modelos, metodologias e outros instrumentos que visem a modernização e melhor adequação da educação às realidades de sua clientela-alvo" (MEC,1987, p.15). 
O SAEB consiste em um levantamento educacional, realizado bianualmente, numa amostra probabilística de alunos de escolas públicas e particulares, urbanas e rurais, de todos os entes federados e do Distrito Federal. No período de 1995 a 2001, foram sendo aprimoradas; além disso, inovações ocorreram. Em 1995, incorporou-se a metodologia de Teoria de Resposta ao Item - TRI (KLEIN, 2011, p. 121).

No entanto, é complexo falar das condições de ensino-aprendizagem dos alunos por meio da coleta de informações socioeconômicas e dos resultados obtidos nos testes padronizados, uma vez que a aprendizagem ocorre ao longo do tempo; são vários anos de escolarização, e a aprendizagem, no decorrer de cinco anos no Ensino Fundamental, não pode ser reduzida a uma avaliação no final dessa etapa do ensino. Franco (2001) aponta a necessidade de esse processo ser medido no início do processo de escolarização e no final, sendo possível acompanhar um desenvolvimento longitudinal.

Entretanto, há influências das políticas de âmbito estadual e municipal, além da gestão da escola, que incidem sobre os resultados, não sendo possível separá-las ou aferi-las. Além disso, há um distanciamento entre a avaliação e a realidade escolar.

No ano de 2005, o SAEB sofreu uma bifurcação, com a Portaria n. 931. Passou a ser composto por dois instrumentos: Avaliação do Rendimento Escolar - ANRESC e Avaliação Nacional da Educação Básica - ANEB. A segunda continua a ser composta pelos questionários socioeconômicos que os alunos e profissionais da educação respondem no dia da aplicação das provas. Essa avaliação mantém as mesmas características do SAEB, sendo aplicada para os alunos do 50 ano, do 9음 ano do Ensino Fundamental e do 3 ano do Ensino Médio.

A ANRESC, também conhecida como Prova Brasil, é aplicada para os alunos do 5 e do 9o ano do Ensino Fundamental, da rede pública e urbana de ensino, em turmas com no mínimo 20 alunos. Em 2005, passou a ofertar resultados não apenas por entes federados, estados e municípios, mas por unidade escolar, o que significou um grande avanço.

\section{A influência dos organismos internacionais no desenvolvimento e na implementação do sistema de avaliação em larga escala no Paraná}

O estado do Paraná foi um dos pioneiros a implementar o sistema de avaliação em larga escala. Esse sistema iniciou com testes de amostragem e testagem, no final da década de 1980, e se intensificou a partir da década de 1990, com a criação do Programa de Avaliação do Sistema Educacional do Estado do Paraná - AVA.

O AVA fazia parte de um dos componentes do Projeto Qualidade no Ensino Público do Estado do Paraná - PQE, contrato com o Banco Interamericano para Reconstrução e Desenvolvimento - BIRD (n. 3766/R), até o ano de 2001. Dentre os documentos publicados do PQE, encontra-se o caderno "Avaliação Escolar: Um Compromisso Ético". O caderno, produzido pela Secretaria de Estado de Educação, em 1993, e explora diversos temas, como: mitos do fracasso escolar; a avaliação escolar como sendo uma questão polêmica; a perspectiva da avaliação professor e 
aluno; e o fato de que a avaliação deve ser um compromisso ético. Esses temas evidenciam a intencionalidade de se institucionalizar um programa próprio de avaliação no estado do Paraná. O documento está envolto em preocupações com os índices de reprovação, evasão e abandono dos alunos na rede estadual de ensino. Nesse caso, a culpa pelos altos índices de reprovação, evasão e abandono é atribuída ao sistema e ao tipo de avaliação realizada, considerada classificatória e excludente, ressaltando-se a necessidade de implementar o programa de avaliação próprio no estado, conforme apresentado no seguinte trecho do caderno, elaborado pela secretaria do estado:

[...] a realização dessa pesquisa permitiu à Secretaria de Estado da Educação institucionalizar um Programa de Avaliação Escolar, a ser implementado nas escolas públicas, a partir do ano letivo de 1994. Esse Programa será organizado com os Núcleos Regionais de Educação e representantes das escolas estaduais no Seminário de Avaliação Escolar, a ser realizado em Curitiba na segunda quinzena de março de 1994. Na superação do fracasso escolar, a comunidade deverá apresentar soluções inovadoras, com características própria, uma vez que deve se considerar a evolução histórica de cada escola, das metodologias e das teorias educacionais que até então sustentaram sua prática avaliativa (PARANÁ, SEED, 1993, p. 67).

O PQE foi um projeto assinado no Governo de Roberto Requião, na primeira gestão, de 1991 a 1994. No entanto, Souza (2001) destaca que o projeto original sofreu modificações posteriores; várias rubricas foram firmadas no decorrer do governo de Jaime Lerner. Assim, O PQE foi implementado com alterações significativas, se comparadas com a versão assinada por Requião. O programa objetivou a implantação de um Programa de Avaliação, com foco nos resultados, além de demonstrar uma preocupação com o envolvimento dos sujeitos, direcionada à eficácia, eficiência, metodologia, custo/benefício e controle.

A preocupação com o aumento dos índices do estado do Paraná e as melhorias propostas por meio da implementação do sistema de avaliação AVA estão expressas no relatório do Banco Mundial (2002), intitulado "PARANA BASIC EDUCATION QUALITY PROJECT". O projeto levou o estado a desenvolver uma cultura de avaliação em todo o sistema do ensino fundamental, por meio de avaliações periódicas e qualitativas, além de implementar programas de apoio, que resultou em um plano de reformas para o sistema educacional paranaense. Componentes essenciais do projeto foram institucionalizados, como capacitação de professores, avaliação quantitativa de aprendizagem dos alunos e sistema de gestão e informações, que foram organizadas com a reorganização da SEED.

Segundo o relatório, dentre os pacotes de projetos incluídos no $P Q E$, os programas referentes à aquisição de materiais didáticos, formação de professores e capacitação dos gestores escolares beneficiaram tantos as escolas estaduais, quanto as escolas municipais. Somam-se a isso recursos destinados a implementar a 
biblioteca nas escolas municipais, bem como transferências de recursos para abarcar custos com o processo de municipalização em municípios com baixa renda, inclusive do sistema de avaliação, como destacado no relatório do BM:

No início de 1995, o objetivo do programa da SEED mudou para introduzir a cultura do parecer e da autoavaliação em nível escolar. O AVA foi concebido para fornecer uma ferramenta de gerenciamento para escolas individuais e todos os níveis da administração estadual e municipal. O sistema se tornou universal em sua aplicação e promoveu a ideia de que cada escola receberia seus próprios resultados e seria capaz de compará-los com aqueles de outras escolas e de vários agrupamentos regionais. Apesar de advertências de Banco de que o programa poderia exceder $a$ capacidade de gerenciamento de projetos, o Estado planejou testar todo ano todos os alunos de escolas estaduais de 4 a a 8 a série do ensino fundamental. Os alunos que frequentavam escolas municipais com um acordo de parceria com o Estado também seriam testados. Na quarta série, cerca de $90 \%$ dos alunos de escolas estaduais e $65 \%$ dos alunos de escolas municipais foram testados anualmente. Na 8 a série, entre $70 \%$ e $90 \%$ dos alunos do Estado e entre $40 \%$ e $60 \%$ dos alunos dos municípios foram testados (BANCO MUNDIAL, 2002, p. 10, tradução nossa, grifos nossos).

Como se pode verificar, o programa AVA obteve grande amplitude no estado do Paraná, abarcando alunos tanto das escolas estaduais como municipais. Como destacado no trecho acima, as ações também visaram a desenvolver o princípio do gerencialismo, por meio do gerenciamento de projetos, monitorando os resultados em nível de estado, município e escola. Os resultados eram fornecidos pelo banco de dados, sendo uma importante ferramenta de gestão a partir de testes anuais, os quais os gestores escolares deveriam utilizar para estabelecer estratégias, capacitação de professores e orientações à comunidade quanto a ações que visem a melhorar a qualidade de educação.

A Secretaria Estadual de Educação, juntamente com Instituto de Desenvolvimento Educacional do Estado do Paraná - FUNDEPAR, contavam com apoio de uma equipe técnica do $P Q E$, bem como dos gerentes e consultores da área e de uma empresa de consultoria contratada, RDR Consultores Associados, que oferecia suporte técnico. O objetivo do programa era universalização do Ensino Fundamental no estado do Paraná; para tanto, o BM viabilizou a reformulação estrutural das formas de gestão do sistema educacional e, principalmente, na gestão da escola, estabelecendo novas raízes de participação entre estado, escola e sociedade. Foram realizados acordos entre BM e SEED; novas rubricas foram realizadas, que resultaram na incorporação de impressão do material do Programa Correção de Fluxo, não previsto no programa inicial de ação para "Material Didático". Mudanças como essas alavancaram as estatísticas do estado do Paraná, elevando as taxas de universalização 
do Ensino Fundamental e reduzindo as taxas de evasão e reprovação, como expresso no Relatório Parana Basic Education Quality Project (2002, p. 6).

O PQE ${ }^{1}$ foi encerrado em 2002; no entanto, passou a ser componente do Projeto Expansão, Melhoria e Inovação no Ensino Médio do Paraná - PROEM, (Contrato com o Banco Interamericano de Desenvolvimento - BID n. 0950/Br). Esse projeto visava à melhoria do Ensino Médio e ao fortalecimento do ensino técnico profissional ${ }^{2}$.O programa AVA, vinculado ao PROEM, perdurou até o ano de 2003; porém, com a descontinuidade do programa, a rede estadual de ensino passou a utilizar os resultados da Prova Brasil e do ENEM, definidos pelo INEP/MEC, para subsidiar as ações para melhoria da qualidade do ensino.

De 2003 a 2012, a partir de estudos referentes aos indicadores de qualidade, a Secretaria do Estado passou a organizar e a desenvolver ações, com o objetivo de implantar e desenvolver um sistema próprio de avaliação para o estado do Paraná. O Programa Sistema de Avaliação da Educação Básica do Paraná - SAEP teve por objetivo "[...] avaliar o rendimento escolar para subsidiar as escolas com informações e dados necessários ao direcionamento pedagógico" (PARANÁ. PAD, 2014, p. 20).

O sistema de avaliação do governo federal (o SAEB, Prova Brasil e IDEB), no entanto, já publiciza dados que podem subsidiar tais ações; porém, há necessidade de acompanhar a respectiva rede de ensino e de monitorar as ações realizadas em âmbito de estado. Inclui-se o interesse em aumentar os financiamentos no que se refere à educação, terceirizar as ações que se referem ao controle da qualidade da educação e ações em âmbito escolar, além de não perder empréstimos e financiamentos, como citado anteriormente, advindos dos organismos internacionais. O documento de avaliação do Projeto Multissetorial para o Desenvolvimento do Paraná - PAD (2012) aponta um valor de U\$350 milhões de dólares do empréstimo proposto para o estado, visto que o custo total do projeto era de U\$ 713,24 milhões de dólares. O objetivo do projeto foi o de "introduzir um novo jeito de governar, enfocando o fornecimento eficiente e eficaz de serviços e fomentando um desenvolvimento mais inclusivo e justo no Paraná" (BANCO MUNDIAL, 2012, p.5). Para atingir esse objetivo, os principais envolvidos no projeto são:

[...] funcionários das secretarias e agências do Governo, porque as atividades envolverão procedimentos, práticas e políticas de recursos humanos; (ii) alunos do ciclo final dos ensinos fundamental e médio e seus pais,; (iii) professores, sindicato dos professores e equipes administrativas de escolas, já que o Projeto apoiará mudanças nas escolas; (iv) profissionais do setor de saúde; (v) usuários do sistema público de saúde e pessoas que atualmente não têm acesso a serviços adequados de saúde, particularmente as mulheres; (vi) estimadas 21 mil famílias rurais que vivem na região central do Paraná, que serão alcançadas pelo Projeto por meio de organizações de produtores e mais 28.800 famílias rurais em outras

\footnotetext{
1 Para aprofundar a pesquisa referente ao PQE, implementado no estado do Paraná, consultar Figueiredo (2009).

2 Para aprofundar o estudo referente ao PQE e ao PROEM, ver Gonçalves (2005). Sobre o PQE, ver também as pesquisas de Maneira (2012).
} 
áreas do Estado que enfrentam questões importantes de manejo de solo e água; e (vii) organizações do setor privado sujeitas a procedimentos de licenciamento ambiental; (viii) prefeituras e consórcios intermunicipais (BANCO MUNDIAL, 2002, p.5).

A partir dos envolvidos no PAD, podemos visualizar a amplitude do projeto e os diferentes setores envolvidos. Para que o projeto atingisse o objetivo proposto, na área da educação, assim como em outros setores, mas em específico nos programas AVA e SAEP -implementado em 2012 - priorizou-se a contratação de técnicos e profissionais, com o objetivo de qualificar gestores, professores e equipe pedagógica, para atuar junto com as escolas. Conforme apresenta o PAD,

Com a finalidade de subsidiar a Coordenação de Planejamento e Avaliação nesse processo de desenvolvimento e implantação do SAEP (nos anos de 2012 e 2013) será contratada empresa/ instituição especializada em avaliação em larga escala.MA contratação ocorrerá mediante dispensa de licitação, cujo Termo de Referência [...] apresenta as especificações dos serviços a serem prestado pela empresa/instituição contratada, tanto do ponto de vista funcional quanto operacional e técnico (PARANÁ. PAD, 2014, p. 24).

O documento ressalta, ainda, que, para o monitoramento contínuo do Programa, será necessária nova contratação, após dois anos da implementação do Sistema de Avaliação, para que sejam realizadas as adaptações necessárias. Assim, pode-se perceber que o SAEP seguiu os moldes da Prova Brasil. No ano de 2012, a equipe da SEED, envolvida com a implementação do programa, elaborou o Caderno de Expectativas de Aprendizagem, outra ação prevista tanto no documento de avaliação do PAD (2012), quanto no Manual Operativo do PAD (2014). Este foi debatido segundo o PAD (2014), com professores e técnicos da rede pública estadual. Segundo o documento, o caderno de expectativas tem por finalidade [...] fomentar a discussão e a reflexão sobre o que se ensina e o que se avalia.

Trata-se de parâmetros gerais para o professor utilizar na elaboração de seus Planos de Trabalho Docente e Diário em sala de aula, auxiliando-o na preparação de seu planejamento, estabelecendo o que é fundamental para cada disciplina e fornecendo diretrizes para servir de base à análise da qualidade do processo educativo desenvolvido em cada uma das escolas, sempre pensando na melhoria da aprendizagem e desenvolvimento dos alunos (PARANÁ, 2014, p.23).

O caderno de expectativas está disponível no portal do Dia a Dia Educação. Além daquilo que foi elaborado por técnicos e professores, foi enviado à escola um modelo piloto do caderno, para que cada entidade realizasse análise dos itens mais 
importantes e incluísse as dificuldades e metas a serem alcançadas, de modo a tornar o documento uma fonte de consulta. Outra ação vinculada ao caderno de expectativas foi a construção e a efetivação do Projeto Político Pedagógico por escola, inserindo as metas e prioridades referentes à avaliação e às ações, a fim de melhorar os índices educacionais de cada instituição.

É possível perceber as intencionalidades do AVA e do SAEP, além da inserção da performatividade e a transposição dos princípios mercadológicos ao sistema educacional. Esses princípios são identificados por meio da implementação de programas como, por exemplo, Prêmio de Referência em Gestão Escolar e Prêmio Educador nota 10, ambos criados em 1998. Além de parceria com Instituto Brasileiro de Qualidade e Produtividade - IBQP, o instituto realizou recomendações que contribuíram para reorganização da SEED, que consistiram na separação da gestão pedagógica e da gestão administrativa (BM, 2002, p. 12). Essas intencionalidades também são comprovadas por meio da contratação de empresas especializadas em avaliação em larga escala e parcerias com a empresa privada, privilegiando os interesses do capital. Dentre as responsabilidades assumidas pelo programa, destacam-se:

a) desenvolver o Sistema de Avaliação da Educação Básica no Paraná em parcerias com empresa/instituição contratada; b) estabelecer parcerias e contratos; c) analisar os resultados da avaliação apresentados pela contratada; d) participar dos debates e encontros nacionais de avaliação; e) estabelecer parcerias interinstitucionais com outros sistemas de avaliação de Educação Básica (PARANÁ. PAD, 2014, p. 22).

O discurso mercadológico na educação é recorrente, visto que as ações desenvolvidas pelo estado do Paraná priorizaram, desde 1992, parcerias com a empresa privada, a fim de propor melhorias, analisar, acompanhar e monitorar as políticas educacionais no estado. No entanto, pouco tem se debatido na própria escola sobre os reais problemas que as instituições enfrentam e que geram baixos índices de desempenho dos alunos, o fato de se inserir um olhar de fora referente aos indicadores da escola deve estar pautado no diálogo e na construção coletiva, na busca de soluções para superar as dificuldades presentes no contexto escolar.

O Sistema de Avaliação da Educação Básica do Paraná - SAEP foi implementado em 2012 e repaginado, com um site próprio, no qual as escolas podem realizar as consultas de seus resultados nas avaliações. Nesses anos, foram contratados profissionais de empresas terceirizadas, especializadas em avaliação em larga escala, para elaboração da matriz de referência, análise dos resultados e proposição de soluções para os baixos índices de desempenho.

Vale lembrar, aqui, a presença do Banco Mundial nesse processo, que, "[...] durante a preparação do Programa, aprovou o Plano de Monitoramento e Avaliação apresentado pelo Estado" (PARANÁ, 2014, p. 32), plano que passou a ser coordenado pelo Instituto Paranaense de Desenvolvimento Econômico e Social - IPARDES. O 
Banco Mundial também foi responsável pela definição de três critérios de monitoramento e avaliação, para poder acompanhar os avanços do programa: indicadores de desenvolvimento, indicadores de monitoramento e indicadores de desembolso. A grande interferência dos organismos internacionais nas políticas educacionais do estado do Paraná justifica o fato de a organização do SAEP ser tão similar ao programa do IDEB.

O PAD possui ampla abordagem; as ações são organizadas a partir de dois componentes: Componente 1, intitulado "Promoção Justa e Ambientalmente Sustentável do Desenvolvimento Econômico e Humano", e componente 2, denominado "Assistência Técnica para Gestão Pública Mais Eficiente e Eficaz". Além disso, os componentes possuem uma suborganização por setores.

O setor 3 ou subcomponente 1.3, Educação, apresenta as ações que o projeto prevê para implementação do Programa Sistema de Avaliação da Aprendizagem no Estado do Paraná, bem como outros projetos em desenvolvimento. O objetivo do subcomponente 1.3 é expresso a seguir:

Este subcomponente apoiará a estratégia do setor de educação do Estado, que tem o objetivo de garantir que todas as crianças no Paraná tenham acesso à educação de boa qualidade. Suas prioridades chave são: (i) melhorar o acesso e a permanência das crianças no ciclo final dos ensinos fundamental e médio; (ii) diminuir o número de alunos acima da idade; e (iii) melhorar os resultados de aprendizado dos alunos. Para reduzir a desigualdade na educação e melhorar o acesso às oportunidades de desenvolvimento humano, a Secretaria de Educação (SEED) enfocará suas intervenções nos municípios com maior necessidade e com baixos indicadores de educação identificados por meio da prova do IDEB e das taxas baixas de matrícula no segundo ciclo dos ensinos fundamental e médio. Este subcomponente apoiará três EEPs estratégicos (BANCO MUNDIAL, 2012, p. 9).

No trecho acima, extraído do documento de avaliação do PAD (2012), pode-se notar as intencionalidades do programa de avaliação SAEP no estado do Paraná. As ações priorizaram a realização de intervenções nos municípios e escolas com baixos índices, com objetivo de auxiliá-las na realização de ações que melhorem a oferta da qualidade da educação, além do aumento de matrículas, redução dos índices de evasão e repetência. Incluíram, como já citado: implementação do Sistema de Avaliação de Aprendizagem, por meio de realização de provas e atividades de disseminação; formações continuadas de professores, por meio do Programa Formação e Ação; e recursos para melhoria da infraestrutura, por meio do Programa Renova Escola.

Dos objetivos específicos do SAEP, ressalta-se o seguinte: disponibilizar dados e informações que sirvam de subsídios à reflexão sobre a prática pedagógica, à luz das Diretrizes Estaduais e dos Cadernos de Expectativas de Aprendizagem. Este objetivo vincula a publicação dos resultados aos Cadernos de Expectativas de Aprendizagem. 
Como o Caderno deve ser atualizado anualmente pelas instituições escolares, esses dados passam a ser utilizados na formação continuada dos servidores, nas formações previstas em calendário escolar, para que haja reflexão acerca dos resultados obtidos em cada escola.

Esse programa é aplicado em todas as escolas estaduais do estado do Paraná, no Ensino Fundamental, para os 6으 e 9o anos, e no Ensino Médio, para os 1 으 e 3 으 anos. Objetiva avaliar o grau de proficiência dos alunos na entrada da segunda etapa do Ensino Fundamental e na saída. O mesmo ocorre com o Ensino Médio. São avaliadas as disciplinas de Português e de Matemática, com a finalidade de acompanhar o desempenho dos alunos e realizar diagnósticos que possam aumentar os índices educacionais no estado; os resultados podem ser consultados no site do SAEP/CAED.

O SAEP divulga a proficiência dos alunos em nível de estado e por escola. O grande problema referente à divulgação dos resultados é o acesso, já que os dados não são disponibilizados à comunidade escolar. Para acessá-los, são necessários uma senha e um login, que são enviados para os diretores da escola. Há dificuldade em debater os dados em âmbito escolar, tendo em vista as condições materiais em que o trabalho ocorre no cotidiano das instituições.

A Secretaria do Estado e o Núcleo Regional de Educação - NRE enviam, para as escolas, sempre no período de formação pedagógica, o material para que sejam trabalhados os resultados do IDEB e do SAEP, a fim de que ocorra um debate no interior da escola. Além disso, há outros materiais, com temáticas definidas e formatadas para que sejam trabalhadas nas formações. Os conteúdos das formações podem ser consultados no site do Dia a Dia Educação, do estado do Paraná. Ao realizar a consulta, nota-se que estas não são flexíveis e ignoram o fato de haver outras demandas que necessitam ser debatidas em âmbito escolar. O monitoramento da realização das formações é realizado por meio de uma avaliação, que o pedagogo da escola deverá postar, após uma semana, no site da SEED, no link que estará disponível, intitulado avaliação da formação em ação ou avaliação da semana pedagógica.

Retira-se, assim, a autonomia da escola, no sentido de promover debates referentes ao que é, de fato, a necessidade dos profissionais que lá atuam, a fim de promover melhorias no ensino e na aprendizagem dos alunos. A forma como formações ocorrem distancia formações continuadas do debate necessário a respeito da situação de cada instituição.

Outra ação do governo do estado do Paraná, visando a aferir o desempenho dos alunos nas avaliações, foi a implementação do Programa de Atividades Complementares na Educação Básica na Rede Estadual de Ensino, publicado em Diário Oficial n8472, de 24 de maio de 2011, pela Resolução 1690, de 27 de abril de 2011. Dentre os programas criados e desenvolvidos, destaca-se o Programa Sala de Apoio à Aprendizagem, realizado no contraturno escolar. $O$ objetivo é atender às dificuldades de aprendizagem de crianças que frequentam o Ensino Fundamental do 60 ao 9o ano, nas aulas de Língua Portuguesa e Matemática; o programa é realizado em dois dias da semana, sendo um para cada disciplina. 
Em 2014, também houve grande redução do orçamento do estado do Paraná para com a educação. Muitas escolas tiveram o pedido de abertura da Sala Apoio negada, o que ocorreu, também, no ano de 2015. A luta no estado do

Paraná por melhores condições de ensino e aprendizagem tem perpassado anos. Foram realizados cortes relacionados à redução do número de funcionários nas escolas, à redução do porte da escola, à redução de $30 \%$ do Fundo Rotativo das escolas, à falta de material didático, merenda, dentre outros. Vive-se atualmente a forte precarização da educação pública no estado do Paraná, comprovada pela greve dos profissionais das escolas estaduais e universidades estaduais, que perdurou mais de 73 dias (LEÃO, 2015).

A política de avaliação em larga escala no estado do Paraná foi intensificada por acordos e orientações com os organismos internacionais. Houve, no primeiro programa, divulgação, em nível de estado, do resultado das melhores escolas, segundo avaliação realizada pelo AVA. Também houve a Premiação, em 2011, das três escolas que apresentaram melhores desempenhos na avaliação realizada no ano de 2000. Essas escolas foram indicadas a participar do Prêmio Referência em Gestão Escolar (criado em 2008, pelo Conselho Nacional de Secretários da Educação CONSED, conjuntamente da União Nacional dos Dirigentes Municipais de EducaçãoUNDIME, da Unesco, e da Fundação Roberto Marinho). Este incentivava as escolas a divulgarem as práticas eficazes de gestão nas escolas estaduais.

\section{Considerações finais}

Rumo à finalização deste artigo, retomam-se alguns pontos importantes. 0 Sistema de Avaliação em larga escala, implementado em nível federal, seguiu princípios neoliberais, assim como no estado do Paraná. Ambos tiveram sua implementação e expansão no decorrer da década de 1990, além de serem financiados pelos organismos internacionais, principalmente pelo Banco Mundial. Esse afinamento, no que se refere ao financiamento do programa, torna-os muito similares. Os programas de avaliação, tanto em âmbito federal, quanto estadual, elencaram medidas a fim de melhorar a qualidade da educação, principalmente nos locais onde havia baixos índices educacionais e poucas condições de infraestrutura. Os levantamentos dos dados realizados pelos indicadores educacionais foram fundamentais para melhorar oferta do ensino, formação dos professores e infraestrutura em diversas regiões do País e no estado do Paraná.

O estado do Paraná foi um dos estados pioneiros na implementação de um sistema próprio de avaliação; iniciou com o Programa AVA, de 1992 a 2002. Um marco de importante destaque no estado foi o PQE, que perdurou de 1994 até 2001; suas ações permitiram, por meio de financiamento do BM, alavancar os índices educacionais, além de reduzir os índices de evasão e repetência.

A partir do $P Q E$, foram inseridos os princípios do gerencialismo na educação, por meio de capacitação dos gestores escolares e ações de caráter gerencial, a fim de promover mudanças no contexto da escola, da família e da sociedade, que, segundo 
os princípios gerenciais, deve assumir responsabilidades referentes à educação. Outro princípio foi o da performatividade, pois professores e gestores devem, de modo eficiente, buscar soluções para os problemas da escola, principalmente no que se refere a baixo rendimento escolar, evasão, repetência e qualidade da educação.

Em 2005, o governo federal lançou a Prova Brasil, que passa a avaliar todos os alunos das escolas municipais e estaduais. Na sequência, foi implementado o IDEB, em 2007, que, juntamente com outros programas, trouxe vários dados que permitiram conhecer a realidade escolar, a partir da proficiência dos alunos nestas duas áreas do conhecimento.

No período de 2003 a 2012, o estado do Paraná desenvolveu ações que o levaram a implementar um sistema próprio de avaliação. O documento do Banco Mundial de Avaliação para implementação do PAD, publicado em 2012, e o

Manual Operativo do PAD, publicado em 2014, demonstram que o Sistema de Avaliação do Estado do Paraná - SAEP, implementado em 2012, foi financiado pelo Banco Mundial. Entre as ações desenvolvidas norteadas pelo BM, destaca-se a elaboração do Caderno de Expectativas, elaborando antes do SAEP, onde as escolas deveriam prever ações que visassem minimizar os problemas referentes aos baixos índices educacionais.

As políticas de formação de professores no estado do Paraná, implementadas por meio do PAD, objetivaram desenvolver habilidades e competências nos gestores e professores, pautadas em treinamentos e reprodução de atividades já formatadas, que contribuíssem para a melhoria do desempenho dos alunos nas avaliações em larga escala. Evidencia-se a SEED como centralizadora dos programas de formação continuada dos profissionais da escola, limitando as ações da escola. Esse programa de formação continuada no estado do Paraná perdura até os dias atuais. Outro Programa advindo do PAD é o Renova Escola, que priorizou ações de melhorias de infraestrutura das unidades escolares.

As políticas de avaliação em larga escala, no Estado do Paraná, de 1992 até a publicação da tese em 2016, estiveram subordinadas aos recursos internacionais, espelhando-se no padrão de avaliação dos países periféricos. Essas políticas utilizam recursos que exigem contrapartida do Estado, sob juros altos, e geram pouco impacto no sistema educacional paranaense. Além disso, há reestruturação da SEED e contratação de consultores educacionais, de modo a tornar o sistema mais eficiente. As políticas de avaliação em larga escala no estado foram intensificadas ao longo dos anos, permeadas por acordos e orientações com os organismos internacionais.

Foram realizadas diversas ações para que os resultados nas avaliações em larga escala fossem os esperados pela SEED, entretanto a descontinuidade de ações como programas como sala de apoio, a falta de debate com as escolas, formação de professores e ações que considerem as peculiaridades de cada município fragilizam os resultados, e não refletem a almejada qualidade da educação.

Ressalta-se que as avaliações em larga escala trouxeram avanços no que refere a melhorias da oferta do ensino; no entanto, ainda são necessárias grandes mudanças para que, de fato, os resultados das avaliações em larga escala, possam expressar ou medir a qualidade da educação. Deve-se realizar análises não apenas coletivamente, 
por meio de médias, mas individualmente, de modo a contribuir para a emancipação do sujeito e para superação das dificuldades de aprendizagem. Fica evidente a necessidade de novas pesquisas sobre as políticas de avaliação no estado do Paraná, seus efeitos e intencionalidades, visto que o governo vem criando novos programas de avaliação que interferem diretamente na organização escolar.

\section{Referências}

BALL. Profissionalismo, gerencialismo e performatividade. Cadernos de Pesquisa, v. 35, n. 126, p. 539-564, set. Dez, 2005.

BANCO MUNDIAL. Prioridades y estrategias para La educación - estudio sectorial Del Banco Mundial. Versión preliminar. Washington, DC: BM, 1996.

BANCO MUNDIAL. Projeto de Melhoria no Ensino Público do Paraná. Relatório da conclusão da implementação. 2002. (Empréstimo n. 3.766-BR).

BANCO MUNDIAL. Relatório da Conclusão da Implementação - Empréstimo 3766-BR. Texto Provisório Revisado. Curitiba, 2002.

BANCO MUNDIAL. Parana Basic Education Quality Project. Report no 24364. [S.I.], 2012.

BANCO MUNDIAL. Projeto Multissetorial para o Desenvolvimento (PAD) do Banco Mundial. [S.I.], 2012.

BONAMINO, Alícia C. de. Tempos de avaliação educacional: o SAEB, seus agentes, referências e tendências. Rio de Janeiro: Quartet, 2002.

BRASIL. II Plano de Desenvolvimento (1975-1979). Brasília: Presidência da República. 1974.

BRASIL. Todos pela Educação. De Olho nas Metas 2013-2014. Brasília.

Disponível em:

http://www.todospelaeducacao.org.br//arquivos/biblioteca/de_olho_nas_metas _2013_141.pdf. Acesso em: 10 jan. 2016.

BRASIL. Instituto Interamericano de Cooperação para a Agricultura. Minuta do relatório da aplicação piloto do sistema de avaliação do ensino público de 19 grau. Brasília: Ministério da Educação,1998.

BRASIL. Lei $\mathbf{n}$. 9394, de 20 de dezembro de 1996. Fixa diretrizes e bases para educação nacional. Diário Oficial da União, Brasília, 23 de dez. 1996.

BRASIL. Leis, Decretos, Pareceres. Plano Nacional da Educação. Apresentação: Vital Didonet. Brasília: editora Plano, 2000.

BRASIL. Constituição. Constituição da República Federativa do Brasil. Promulgada em 5 de outubro de 1988. 37. Ed. Atual. E ampl. São Paulo: Saraiva, 2005. 
BRASIL. Ministério da Educação e do Desporto. Minuta do relatório nacional do sistema de avaliação do ensino básico, ciclo de 1990. Brasília: Ministério da Educação, 1992.

BRASIL. Plano de Desenvolvimento da Escola - PDE-ESCOLA. 2016.

COELHO, Maria Inês de Matos. Vinte anos de avaliação da educação básica no Brasil: aprendizagens e desafios. Ensaio: Aval. Pol. Públ., Rio de Janeiro, v. 16, n. 59, p. 229258, abr./jun, 2008.

FONSECA, Francisco; BELTRÃO, Ricardo E. V; PRADO, Otávio. Avaliando a capacidade de governo: reflexões sobre a experiência do Prêmio "Municípios que fazem render mais" (2010 e 2011). Rer. Adm. Pública. Rio de Janeiro, v. 47, n.1, jan./fev, 2013, p. 249-272.

FONSECA, M. O Banco Mundial como referência para justiça social no terceiro mundo: evidências do caso brasileiro. In.: Revista da Faculdade de Educação. Vol. 24, n.1, São Paulo: Jan./jun. 1998. Disponível em: http://www.scielo.br/scielo.php? script=sci_arttext\&pid=S010225551998000100004 Acesso em: Mar./2020.

FRANCO, Cresso. O SAEB - Sistema de Avaliação da Educação Básica: potencialidades, problemas e desafios. Revista Brasileira de Educação, 2001, p. 127-133.

FREITAS, Luiz C. de. Eliminação adiada: o ocaso das classes populares no interior da escola e a ocultação da (má) qualidade do ensino. Educação \& Sociedade, Campinas, v. 28, n. 100 - Especial, out, 2007, p. 965-987.

GONÇALVES, Luzia de F. Programa de Avaliação do Sistema Educacional do Estado do Paraná - AVA - 1995/2002: Uma Avaliação a Serviço da Formação Humana, ou de Favorecimento do Mercado Econômico? 2005. 184 fls.. Dissertação (Mestrado em Educação). Universidade Federal do Paraná (UFPR), Curitiba, 2005.

HEYNEMAN, Stephen P. Avaliação de Qualidade da Educação: Lições para o Brasil. In: MELLO E SOUZA, Alberto de. (Org.). Dimensões da Avaliação Educacional. 3. ed. Petrópolis: Vozes, 2011, p. 35-62.

KLEIN, Ruben. Testes de rendimento escolar. In: MELLO E SOUZA, Alberto de. (Org.). Dimensões da Avaliação Educacional. 3. ed. Petrópolis: Vozes, 2011, p. 110-138.

PARANÁ. Secretaria de Estado da Educação. Proposta técnica e financeira AVA 2000. Programa de Avaliação do rendimento escolar - PQE: Programa Qualidade de Ensino. Aplicação e correção. Curitiba, 2000.

PARANÁ. Secretaria do Estado da Educação. Projeto Qualidade no Ensino Público do Paraná. Curitiba: Secretaria de Estado da Educação, 2002.

PARANÁ. Secretaria de Estado da Educação. Relatório de conclusão da implementação do empréstimo de 69 milhões de dólares norte-americanos ao estado do Paraná, Brasil, destinado ao Projeto Qualidade no Ensino Público do Paraná. Curitiba, 2002. 
PARANÁ. Cadernos Temáticos: avaliação institucional. Curitiba: Secretaria de Estado da Educação, 2005.

PARANÁ. Programa de Atividades Complementares na Educação Básica na Rede

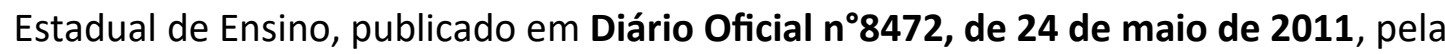
Resolução 1690, de 27 de abril de 2011.

PARANÁ. Secretaria de Estado do Planejamento e Coordenação Geral; Secretaria da Educação. Projeto Multissetorial para o Desenvolvimento do Paraná - PAD. Manual Operativo do Projeto - MOP. Paraná, v.4, jan, 2014.

PARANÁ. Secretaria de Estado da Educação. Dia a Dia Educação: Portal Educacional do Estado do Paraná - PDE. [S.I., 2015?]. Disponível em:

http://www.gestaoescolar.diaadia.pr.gov.br/modules/conteudo/conteudo.php?c onteudo=28>. Acesso em: 01 jun. 2015.

PREAL. Programa de Promoção da reforma Educativa na América Latina e Caribe. Um boletim da educação na América Latina. Chile:2001.

SOLIGO, V. Qualidade da Educação: relações entre características de contexto e os resultados das avaliações em larga escala nos municípios de pequeno porte da Região Sul do Brasil. São Leopoldo, 2013, 214 fls. Tese (Doutorado em Educação) - Programa de Pós-Graduação em Educação. Universidade do Vale do Rio dos Sinos (UNISINOSO, São Leopoldo, 2013.

SOUZA, S. A. Gestão Escolar Compartilhada: democracia ou descompromisso? São Paulo: Xamã, 2001.

WERLE, F. Políticas de Instrução Pública no século XIX como eco de experiências internacionais. Revista Educação, Porto Alegre, v.31, n.2, p.173181, maio/ago. 2008. 